\title{
Retrospective analysis: the research on Mycobacteria in Basilicata from 1977 to 2012
}

\begin{abstract}
The aim of this report is to describe the work of the mycobacterial laboratory operating in the Anti-Tuberculosis Dispensary of Matera for tuberculosis laboratory diagnostics essential to the clinicians to define the pathological findings. The laboratory analyzed all materials coming from Matera and its territory (including the materials coming from the local hospital). In 1998 The Region of Basilicata decided that the laboratory (owing to its experience) should be the referential center for the research of mycobacteria. In 2002 the Anti-Tuberculosis Dispensary of Matera was closed and its structures were transferred to the local hospital including the mycobacterial laboratory which worked for all the region by this time. The results of the mycobacterial research regarding Matera and its province from 1977 to 1998 and all the region of Basilicata from 1999 to 2012 are described in this article.
\end{abstract}

Volume 3 Issue 5 - 2018

\author{
Leonardo Buono, Caterina Colonna, \\ Giuseppe Montesano \\ Madonna delle Grazie Hospital, Italy
}

Correspondence: Leonardo Buono, Madonna delle Grazie Hospital, Italy, Email leobuono@alice.it

Received: June 28, 2018 | Published: October 2, 2018

\section{Introduction}

The mycobacterial laboratory was devoted to the search of the Koch bacillus in the pathological materials through the microscopical examination, the examination of the culture, identification and antibiogram. The scientific progress and technical innovation have remarkably improved the mycobacterial diagnostic possibilities and consequently rapid tests of high sensibility and specificity have been developed such as the gene amplification tests used directly on the clinical samples and gene probes for the identification of non-tuberculosis mycobacteria (NTMs) which have substituted the biochemical tests of uncertain identification.

Since 1995 a surveillance system of the resistance to anti tuberculosis pharmaceutical products operates at national level according to the guidelines of WHO (Proyet SMIRA Studio Multicentro Italiano Resistenze Antitubercolari) and under the coordination of the Istituto Superiore di Sanità. The mycobacterial laboratory is involved in this project since 1998. This report wish to give a contribution to the knowledge of the results of the research on the tuberculosis bacillus about Matera and province from 1977 to 1998 and About Basilicata from 1999 to $2012^{1,2}$

\section{Materials and methods}

From 1977 to 2012 a total of 39,121 samples of pathological materials were examined, including 26,336 (67.3\%) respiratory samples (sputum, bronchoalveolar lavage (BAL), bronchoaspirate (BAS), gastric and tracheal aspirates) 4,975(12.7\%) genitourinary samples, 478(1.3\%) liquor, 6,127(15.7) cavitary fluids, 785(2.6\%) purulent and aspirated materials, $420(1.1 \%)$ other materials.

In the above Table 1 the analyzed materials come from Matera and then from Basilicata.

Most of the materials are from respiratory origin and they are much more numerous than non-respiratory materials both for Matera and Basilicata. ${ }^{3}$

The materials were treated with a solution of $\mathrm{NaOH}$ at $4 \%$ with the addition of litmus and neutralized with HCL after 15 minutes. Then they were decontaminated, fluidized and concentrated according to the standard methods of CDC using a solution of N-acetyl-L-cysteine and sodium hydroxide. ${ }^{4,5}$ This solution is added in a volume equal to that of the sample and left at room temperature for 15 minutes, homogenized by spinning and then neutralized with a phosphate buffer and centrifuged. The supernatant was eliminated and the sediment was used for the microscopic examination, the culture and the amplification test. The samples probably sterile as the cavitary fluids were added to a buffer solution and the sediment was used for the subsequent analytic phases. The Zielh-Neelsen warm staining method was used and later the The Kinyoun cold staining method. The isolation of microorganisms was made on solid medium Lowstein Jensen and fluid medium MGIT (Becton - Dickinson). The results of microscopic examination of all samples confirmed that the percentage of positive mycobacteria was higher for the respiratory material.

Besides microscopic examination, later gene amplification was used directly on treated clinical material reducing response time for diagnosis. The method was based on SDA (Strand Dispacement Amplification) technology effected in weekly work sessions and if demands were urgent, in one day time. This method was used also for extra pulmonary samples taking into account that in this case it was not the optimum one.

In the Table 2 below.

The data obtained from 1999 to 2012 for the whole Baslicata. It is evident that the possibility

of diagnosis improved using gene amplification. ${ }^{6-8}$

The isolation of microorganisms was made on solid medium Lowstein-Jensen (weekly controlled) and after some time was added manual fluid medium MGIT (Mycobacteria Growth Indicator Tube, Becton - Dickinson) with direct visibility of fluorescence. Later on the system Bactec 960 was used for fluid medium. In this case the tubes were incubated at $37^{\circ} \mathrm{C}$ and when a fluorescence was revealed the bacterial colonies were examined at the microscope. The cultures on solid medium were eliminated after two months, the ones on fluid medium after 40 days. The positive results were obtained first on fluid and then on solid medium. Since they rarely appeared on solid medium, it was necessary to use both the medium as a routine. , $, 7,9-15^{2}$ 
Totally were isolated $887 \mathrm{M}$. Tubercolosis of which 715(80.6\%) from respiratory material, $172(19.4 \%)$ from extra pulmonary material: genito-urinary $115(12.9 \%)$, liquor $23(2.5 \%)$, cavitary fluids (pleural, ascetic, etc.) 14(1.59\%), purulent materials and aspirates of various origins (gluteal pus from psoas abscess, intervertebral lymphoglandular and scrotal aspirates) $14(1.59 \%)$, various materials (biopsies, faeces and blood) $4(0,45 \%)$.

During the period 1999-2012, in Matera and Potenza territory were isolated 60 non-Tuberculous Mycobacteria (NTMs), which were sent for species identification to the Centre of reference for Mycobacteria of the Region of Tuscany, which made a high-performance liquid chromatography (HPLC) study. Identification was subsequently made by hsp65 gene sequencing at the molecular biology laboratory of the X-life Centre, annexed to the Laboratory of Clinical Pathology of the "Madonna delle Grazie". (Data published in Microbiologia Medica). ${ }^{13}$

The results obtained from 1975 to 1998 in Matera and from 1999 to 2012 all over Basilicata through the operating sanitary structures are described in Table 4.

It was observed the sensitivity of the M. tuberculosis strains to streptomycin (SM), isoniazid (INI), rifampicin (RMP), ethambutol (ETB) isolated with the method of the multiple proportions according to Canetti and coll. ${ }^{16}$ It was used the indirect method after isolating the strain in L-J medium and only in a few cases the direct method was used. Later was used the fluid medium MGIT for the observation of the resistance. ${ }^{9,10,16}$

The graph below shows the total of the isolated sensitive and resistant in the different periods. It can be noted an evident reduction of both the isolated and the resistance from 1977 to 1998 and an increase from 1999 to 2012 due to the more numerous strains coming from all the region without knowing if they had already been treated with anti tuberculosis pharmaceutical products. Moreover it must be said that among the materials coming from Potenza and its territory there were also those obtained from immigrants.

These data were sent to the Public Health Institute.

The graph shows the results of the isolated and resistance referred to the period 1977-2012, partly published. The period 1997-2000 includes the results of different two year period (1997-1998 for Matera and 1999-2000 for Basilicata). However in this report the positive samples isolated from one patient in different periods have not been taken into consideration. ${ }^{11,12}$

Our observations do not discriminate the primary resistance from the secondary one, owing to the difficulty to obtain the right information from the place of origin.

From 1977 to 1998106 isolated strains out of 577 and 65 out of 310 from 1999 to 2012 have been recorded. All strains were examined for their sensitivity to anti tuberculosis pharmaceutical products of first line (streptomycin, isoniazid, rifampicin, ethambutol).The results are shown in the Table 5

As regards the resistance to single pharmaceutical products during the periods considered, it must be said that it is more frequent to Streptomycin, Streptomycin, Isoniazid respectively. Only one case to Ethambutol.

Matching of anti tuberculosis pharmaceutical products are described in Table $7 .{ }^{17}$

Table I Origin of samples

\begin{tabular}{|c|c|c|c|c|c|c|}
\hline \multirow[t]{2}{*}{ Type of sample } & \multicolumn{2}{|c|}{$\begin{array}{l}\text { Matera e provincia 1977- } \\
1998\end{array}$} & \multicolumn{2}{|c|}{$\begin{array}{l}\text { Basilicata 1999- } \\
2012\end{array}$} & \multicolumn{2}{|c|}{$\begin{array}{l}\text { Periodo di osservazione } 1977 \\
2012\end{array}$} \\
\hline & $\mathbf{n}^{\circ}$ & $\%$ & $\mathbf{n}^{\circ}$ & $\%$ & $\mathrm{n}^{\circ}$ & $\%$ \\
\hline Sputum, bal, bas aspirates gastrico & 16,873 & 68.9 & 9,463 & 66.4 & 26,336 & 67.3 \\
\hline Genito-urinary materials & 3,089 & 12.4 & 1,886 & 13.2 & 4,975 & 12.7 \\
\hline Liquor & 294 & 1.1 & 184 & 1.3 & 478 & 1.2 \\
\hline $\begin{array}{l}\text { Cavitary fluids: pleu., peric., perit., } \\
\text { synov. }\end{array}$ & 3,820 & 15.3 & 2,307 & 16.2 & 6,127 & 15.7 \\
\hline \multirow{3}{*}{$\begin{array}{l}\text { Purulent materials and aspirates } \\
\text { Miscel materials (biopsies, blood, } \\
\text { faeces) }\end{array}$} & 523 & 2.1 & 262 & 1.8 & 785 & 2.6 \\
\hline & 267 & 1.1 & 153 & 1.1 & 420 & 1.1 \\
\hline & 24,815 & 100 & 14,255 & 100 & 39,121 & 100 \\
\hline
\end{tabular}

Table 2 Microscopic examination on different materials period 1977-2012

\begin{tabular}{lcccccc}
\hline & Resp. material & Non resp. material & \multicolumn{2}{c}{ Total } & \\
\hline & & & & & & \\
& $\mathbf{n}^{\circ}$ & $\mathbf{\%}$ & $\mathbf{n}^{\circ}$ & $\mathbf{\%}$ & $\mathbf{n}^{\circ}$ & $\mathbf{\%}$ \\
\hline Positive & 419 & 58.6 & 71 & 41.2 & 490 & 55.2 \\
Negative & 296 & 41.4 & 101 & 58.7 & 397 & 44.8 \\
Total & 715 & 100 & 172 & 100 & 887 & 100 \\
\hline
\end{tabular}


Table 3 Correlation between positive microscopic examination and amplification referring to 310 cultures. period I999-20I 2

\begin{tabular}{lllll}
\hline & Microscopic & $\mathbf{\%}$ & Amplification & \% \\
\hline Positive & 165 & 56 & 289 & 93.3 \\
Negative & 145 & 44 & 21 & 6.7 \\
Total & 310 & 100 & 310 & 100
\end{tabular}

Table $4 \mathrm{M}$ tuberculosis isolated from clinical respiratory e non respiratory samples. Period I977-20I2

\begin{tabular}{|c|c|c|c|c|c|c|}
\hline \multirow[t]{2}{*}{ Materiale clinico } & \multicolumn{2}{|c|}{$\begin{array}{l}\text { Matera } \\
1977-1998\end{array}$} & \multicolumn{2}{|c|}{ Basilicata 1999-2012 } & \multicolumn{2}{|c|}{$\begin{array}{l}\text { Periodo } \\
\text { 1977-2012 }\end{array}$} \\
\hline & $n^{\circ}$ & $\%$ & $n^{\circ}$ & $\%$ & $n^{\circ}$ & $\%$ \\
\hline Respiratory material & 448 & 78 & 267 & 86.1 & 715 & 80.1 \\
\hline Genitourinary samples & 94 & 16.8 & 21 & 6,7 & 115 & 13.1 \\
\hline Liquor & 14 & 2.4 & 9 & 2.9 & 23 & 2.6 \\
\hline Cavitary fluids (pleu., peric.,asciti. sinov.) & 11 & 1.9 & 5 & 1.6 & 16 & 1.8 \\
\hline Purulent and aspirated materials & 9 & 1.5 & 5 & 1.6 & 14 & 1.6 \\
\hline Other materials (biopsy, blood, faces) & 1 & 0.17 & 3 & 0.96 & 4 & 0.4 \\
\hline Total & 577 & 100 & 310 & 100 & 887 & 100 \\
\hline
\end{tabular}

Table 5 Resistance to pharmaceutical products of the trains isolated

\begin{tabular}{lllll}
\hline Periods & Isolated & Sensibile & Resistent & \% \\
\hline Matera 1977-1998 & 577 & 471 & 106 & 18.4 \\
Basilicata 1999-2012 & 310 & 245 & 65 & 21.6 \\
Total 1977-20012 & 877 & 716 & 171 & 19.5 \\
\hline
\end{tabular}

Table 6 Resistance to single pharmaceutical products during the periods considered

\begin{tabular}{lllllll}
\hline \multirow{2}{*}{ Pharmaceutical products } & \multicolumn{2}{l}{$\begin{array}{l}\text { Matera } \\
\mathbf{1 9 7 7 - 1 9 9 8}\end{array}$} & \multicolumn{2}{l}{$\begin{array}{l}\text { Basilicata } \\
\mathbf{1 9 9 9 - 2 0 1 2}\end{array}$} & \multicolumn{2}{l}{$\begin{array}{l}\text { Total } \\
\mathbf{1 9 7 7 - 2 0 1 2}\end{array}$} \\
\cline { 2 - 7 } Streptomycin & $\mathbf{n}^{\circ}$ & $\mathbf{\%}$ & $\mathbf{n}^{\circ}$ & $\mathbf{\%}$ & $\mathbf{n}^{\circ}$ & $\mathbf{\%}$ \\
\cline { 2 - 7 } Isoniazid & 40 & 6.9 & 31 & 10.0 & 71 & 8.0 \\
Streptomycin & 6 & 1.0 & 3 & 1.0 & 9 & 1.0 \\
Ethambutol & 13 & 2.3 & 10 & 3.2 & 23 & 2.6 \\
\hline
\end{tabular}

Table 7 Development of the Pharmaceutical products matching

\begin{tabular}{|c|c|c|c|c|c|c|}
\hline \multirow{2}{*}{ Pharmaceutical products } & \multicolumn{2}{|c|}{$\begin{array}{l}\text { Matera } \\
1977-1998\end{array}$} & \multicolumn{2}{|c|}{$\begin{array}{l}\text { Basilicata } \\
1999-2012\end{array}$} & \multicolumn{2}{|c|}{$\begin{array}{l}\text { Total } \\
\text { 1977-2012 }\end{array}$} \\
\hline & $n^{\circ}$ & $\%$ & $n^{\circ}$ & $\%$ & $n^{\circ}$ & $\%$ \\
\hline MonoR & 59 & 10.2 & 45 & 14.5 & 104 & 11.9 \\
\hline PoliR & 29 & 5.0 & 15 & 4.8 & 44 & 5.0 \\
\hline MDR & 19 & 3.3 & 5 & 1.6 & 24 & 2.7 \\
\hline
\end{tabular}




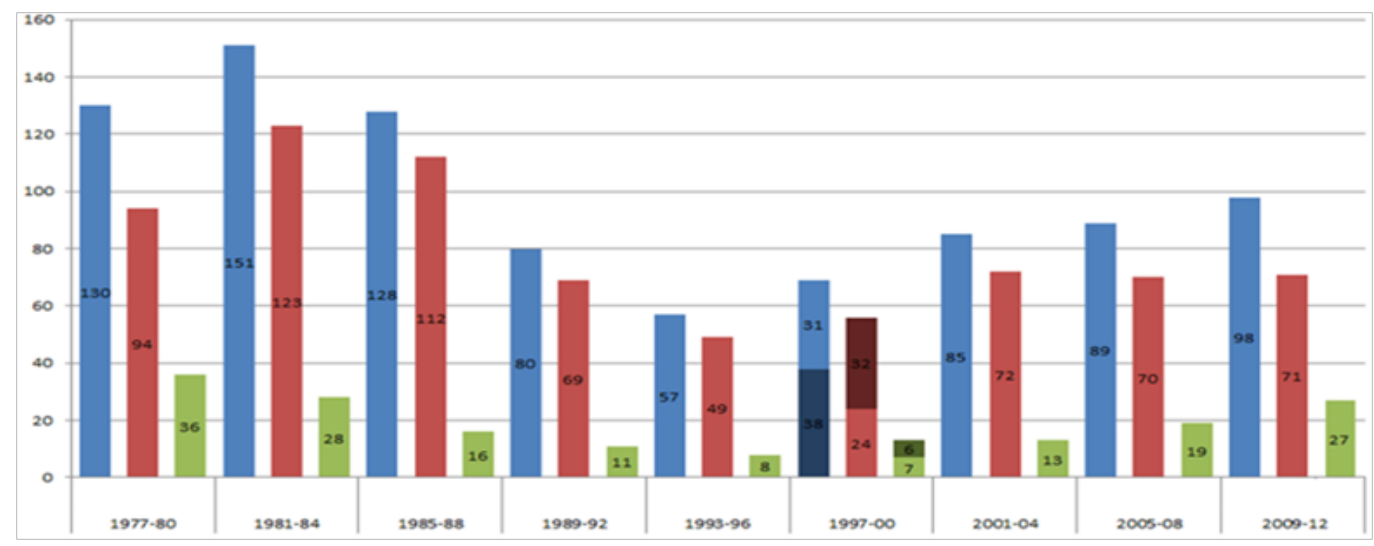

Figure I Isolated strains sensitive and resistant distributed for four-year periods.

\section{Conclusion}

The relevant point is that during the periods 1977-1998 and 19992012 all the samples for the search of the tuberculosis bacillus coming respectively from the sanitary structures of Matera and Potenza were sent to the Micobacterial Laboratory of the Anti-Tuberculosis Dispensary and it continued to accept all the samples of the whole Basilicata when it was transferred to the hospital "Madonna delle Grazie" of Matera.

The resistance to the anti tuberculosis pharmaceutical products regarding only to people from Matera and province was on the whole of $18.4 \%$ during the years $1977-1998$ and in detail 6.9 to SM, 1.0 to INH e 2.3 to RMP. These data from one hand confirm the higher resistance to streptomycin, as it is reported in literature, on the other are different from the publications regarding isoniazid and rifampicyn, probably because rifampicyn is more frequently used in the various pathologies. The data of the whole region during the years 1999-2012 are almost the same being of $21.0 \%$.

Taking into consideration the years 1977-1998 the percentage of MDR strains was of $2.7 \%$. The reason was probably due to a bad use of the pharmaceutical products and to the lateness with which the patients got medical advice. It is important to say that in the second period the resistance to MDR was isolated from the sputum of a HIV positive patient and from the faces and blood of another HIV positive patient, from a patient not adequately treated and other two foreign patients who had followed a therapy, not specified, in their countries of origin.

Even if Basilicata is a small region with a population of less than 600.000 inhabitants, 400.000 in the province of Potenza and 200.000 in the province of Matera, it is desirable that the research on micobacteria done so far by specialists can be continued in one laboratory working for the whole region.

\section{Acknowledgements}

None.

\section{Conflicts of interest}

The author declares there are no conflicts of interests.

\section{References}

1. Kubica GP, Gross WM, Hawkins JE, et al. Level of laboratory services mycobacterial diseases. Am Rev Respir Dis.1975;112(6):773-787.

2. Maher D, Chaulet P, Spinaci S, et al. Treatment of tuberculosis. Guidelines for national programmes. 1997 .

3. Piersimoni C. La diagnostica dei Micobatteri in Italia. Microbiologia Medica. 2005;20(1):8-11.

4. Kubica GP, Dye WE, Cohen ML, et al. Sputum digestion and decontamination with $\mathrm{N}$-acettyl-Lcysteine sodhydroxide for culture of mycobacteria, Am Rev Respir Dis.1963;87:775-779.

5. CLSI Laboratory detection and identification of mycobacteria approved guideline. clsi. 2008.

6. Nucleic acid amplification for tuberculosis. MMWR. 1996;45:950-952.

7. Mazzarelli G, Rindi L, Piccoli P, et al. Evolution of the of the BDProbetec ET system for direct detection of Mycobacterium tuberculosis in polmonarry and extrapolmonary samples: a multi center study. $J$ Clin Microbiol. 2003;41(4):1779-1782.

8. Chiaradonna P, Tronci M. Ed contaminazione e coltura. In: Tortoli E, Piersimoni C, Scarparo C, et al. editors. Micobatteriologia Clinica Ed. Selecta Medica: Pavia; 2013.

9. Hanna BA, Ebrahimzadeh A, Eliot LB, et al. Multicenter evaluation of the BACTEC MGIT 960 system for recovery of mycobacteria. J Clin Microbiol.1999;37(3):748-752.

10. Fattorini L, Migliori G, Cassone A, et al. Multicentre Study on Resistece to Antitubrculosis Resistent to Antituberculosis Drugs (SMIRA) Group, Proficiency testing of first-line second-line antituberculosis drug in Italy. Eur Respir J. 2012;39:1263-1266.

11. Buono L, Mazzarone R. Resistenze micobatteriche rilevate in provincia di Matera (osservazioni relative al quadriennio 1977-80) Arch Monaldi.1981;36:131-141.

12. Buono L, Montesano G. Resistenze micobatteriche e farmacoterapia: Considerazioni su una casistica. Lotta contro la tubercolosi e Malattie Polmonari Sociali. 1991;61:444-448.

13. Buono L, Montesano G. Epidemiology of mycobacteria infections in Basilicata, Italy: 1999-2012. Microbiologia Medica.2017;32(1).

14. La tubercolosi in Italia. Ministero della salute, Istituto Superiore di Sanità, Regione Emilia Romagna. 2008. 
15. Tortoli E, Cichero P, Piersimoni C, et al. Use of BACTEC MGIT 960 for recovery of mycobacteria from clinical specimens multicenter study.J Clin Microbiol.1999;37(11):3578-3582.

16. Canetti G, Rist N, Grosset J, Mesure de la sensibilité du bacilli tubercleux aux drogues antibacillaires par le metthode des propotions. Rev Tuberc. Pneumol. 1963;27:217-272.

17. La tubercolosi in Italia. Rapporto 2008 (ISS, Regione Emilia e Romagna). 